\title{
GESTÃO DEMOCRÁTICA: o processo representativo nos Conselhos Escolares
}

\section{DEMOCRATIC MANAGEMENT: the representative process in Schools Councils GESTIÓN DEMOCRÁTICA: el proceso representativo en los Consejos Escolares}

\author{
Carlos André Sousa Dublante \\ Professor Doutor do Departamento de Educação II da \\ Universidade Federal do Maranhão (UFMA). \\ São Luís-MA, Brasil. \\ cdublante@terra.com.br \\ Antônio Cabral Neto \\ Professor Doutor do Programa de Pós-Graduação em Educação da \\ Universidade Federal do Rio Grande do Norte (UFRN). \\ Natal-RN, Brasil. \\ acabraln@yahoo.com.br
}

Resumo: O presente artigo tem o objetivo de contribuir com as discussões sobre o processo de democratização da escola por meio da representação dos segmentos dos professores, pais, alunos e funcionários de Conselhos Escolares. Nessa perspectiva, entendemos a participação como um processo de formação dos sujeitos para atuar politicamente em seu cotidiano e no espaço da escola, problematizando sobre as condições de funcionamento e dificuldades existentes para construírem coletivamente propostas para a melhoria das condições apresentadas. Em seu desenvolvimento discutimos a democratização da escola como resultado das lutas pela democracia, realizadas no contexto dos anos de 1980 e que propiciaram a institucionalização de mecanismos que possibilitem o envolvimento da comunidade na gestão da escola, entre os quais os Conselhos Escolares. Na constituição destes tornam-se imprescindíveis a representação proporcional de todos os segmentos que compõem a escola a fim de assegurar a diversidade de opiniões e a democratização das votações dos assuntos discutidos durante as reuniões. Adotamos como método o materialismo histórico dialético, tendo em vista que este possibilita a compreensão do real a partir de suas múltiplas determinações; e, como procedimentos a revisão bibliográfica, pesquisa documental e entrevista semiestruturada. Os resultados da pesquisa evidenciam que embora a escolha dos representantes seja realizada por meio de eleições, as decisões deliberadas nos conselhos seguem as orientações dadas pelas gestoras das escolas, tendo, ainda, como um dos principais limites do processo representativo a falta de envolvimento de representantes, principalmente dos pais $\mathrm{e}$ alunos nos processos decisórios.

Palavras-chave: Conselho escolar. Participação. Representação.

\begin{abstract}
The article aims to contribute to the discussions about the democratization process of the school through representation of the segments of teachers, parents, students and School Councils officials. In this perspective, we understand participation as a process of formation of the subject to act out politically in their daily lives and in the school space, problematizing on the conditions of operation and difficulties to collectively construct proposals to improve the presented conditions. In its development we discussed the democratization of the school as a result of the struggles for democracy, carried out in the context of the 1980s and that allowed the institutionalization of mechanisms that allow community involvement in school management, among School Councils. In the constitution of these becomes essential the proportional representation of all the segments that compose the School in order to assure the diversity of opinions and the democratization of the voting of the subjects discussed during the meetings. We adopt dialectical historical materialism as a method, considering that this allows the understanding of the real from its multiple definitions; and as procedures the bibliographic review, documentary research and semistructured interview. The results of the research evidence that although the choice of representative is made by means of election, deliberation discussions in councils follow the guidelines given by the school administrators, having as one of the main limits of the representative process the lack of involvement of representatives principally of parents and students in the decision process.
\end{abstract}

Keywords: School council. Participation. Representation.

Resumen: El presente artículo tiene el objetivo de contribuir con las discusiones el proceso de democratización de la escuela por medio de la representación de los segmentos de los profesores, padres, alumnos y funcionarios de Consejos Escolares. En esa perspectiva, entendemos la participación como un proceso de formación de los sujetos para actuar políticamente en su cotidiano y en el espacio de la escuela, problematizando sobre las condiciones de 
funcionamiento y dificultades existentes para construir colectivamente propuestas para a mejoría de las condiciones presentadas. En su desarrollo discutimos la democratización de la escuela como resultado de las luchas por la democracia realizadas en el contexto de los años de 1980 y que propiciaron la institucionalización de mecanismos que posibiliten el envolvimiento de la comunidad en la gestión de la escuela, entre ellos, los Consejos Escolares. En la constitución de estos tornase imprescindible la representación proporcional de todos los segmentos que componen la escuela a fin de asegurar la diversidad de opiniones y la democratización de las votaciones de los asuntos discutidos durante las reuniones. Adoptamos como método el materialismo histórico dialéctico, teniendo en vista que éste posibilita la comprensión del real a partir de sus múltiples determinaciones; y como procedimientos la revisión bibliográfica, la investigación documental y la entrevista semiestructurada. Los resultados de la investigación evidencian que a pesar de que la selección de los representantes sea realizada por medio de elecciones, las decisiones deliberadas en los consejos siguen las orientaciones dadas por las gestoras de las escuelas, teniendo aún como uno de los principales límites del proceso representativo, la falta de envolvimiento de representantes, principalmente, de los padres y alumnos en los procesos decisorios.

Palabras clave: Consejo escolar. Participación. Representación.

\section{INTRODUÇÃO}

A gestão da escola, idealizada em uma perspectiva democrática, tem o objetivo de superar as práticas fragmentadas e descontextualizadas com as quais a escola cumpria as determinações do Estado, para configurar-se no reconhecimento da importância que a comunidade possui na participação das decisões e na construção do plano de ação da escola, fortalecendo a democratização do processo pedagógico, o que pode ocorrer na gestão dos sistemas de ensino e, especificamente, na gestão das instituições de educação públicas. (LÜCK, 1997, 2010). A necessidade de fortalecer essa discussão coloca a gestão da escola no centro dos debates que permeiam a área educacional, tanto no desenvolvimento de suas políticas, quanto na institucionalização de mecanismos que envolvam a comunidade escolar nos processos decisórios.

O presente artigo tem o objetivo de contribuir com as discussões sobre o processo de democratização da escola por meio da representação dos segmentos dos professores, pais, alunos e funcionários nos Conselhos Escolares. A sua relevância está nas reflexões que fazemos em relação aos caminhos construídos, por força das reivindicações dos movimentos sociais, com o objetivo de ampliar os espaços participativos. A análise teórico-metodológica está pautada no materialismo histórico dialético, tendo em vista a possibilidade de compreendermos o objeto a partir de suas múltiplas determinações, em uma visão em que os processos históricos, sociais, políticos e econômicos influenciam na determinação do real e nos mecanismos utilizados para sua superação. Além disso, adotamos como procedimentos a pesquisa bibliográfica, análise documental e entrevistas semiestruturadas, que são "[...] utilizada[s] para recolher dados descritivos na linguagem do próprio sujeito, permitindo ao investigador desenvolver intuitivamente uma idéia sobre a maneira como os sujeitos interpretam aspectos do mundo" (BOGDAN; BIKLEN, 1994, p. 134), essas entrevistas serão realizadas com os representantes dos segmentos presentes nos Conselhos das escolas.

No desenvolvimento do artigo retomamos alguns elementos históricos que permeiam esse debate, tomando como marco os anos de 1980, momento de redemocratização do Brasil e de luta pela melhoria das condições educacionais, incluindo a sua gestão. Na sequência tratamos acerca do papel dos conselhos escolares, como mecanismo de participação da comunidade escolar e local nos processos deliberativos da escola, nesse aspecto fazemos reflexões sobre o processo de representação, mais especificamente, em relação aos procedimentos adotados pelas escolas para a escolha dos conselheiros e os limites existentes na representação. A elaboração do artigo resulta dos dados obtidos durante a pesquisa de tese de doutorado intitulada "Gestão Democrática: o processo de representação nos Conselhos Escolares da rede pública municipal de ensino de São Luís/MA", defendida em 2016 no Programa de Pós-Graduação em Educação (PPGED) da Universidade Federal do Rio Grande do Norte.

\section{DEMOCRATIZAÇÃO DA ESCOLA: um debate permanente}

A discussão sobre a democratização da educação e, em consequência, da escola pública, no Brasil, apresenta-se como ponto de pauta desde a década de 1930, vinculada às reivindicações do movimento dos Pioneiros da Educação Nova, para o qual a gestão democrática engloba a ação de 
educadores, de movimentos sociais e da sociedade em prol de uma educação pública de qualidade social, garantida pela participação permanente de todos. Essa luta se intensificou na década de 1980, com a redemocratização do país e a elaboração de uma nova Constituição, promulgada em 1988.

Além de tentar superar a centralização e o autoritarismo vigentes na esfera educacional, a luta pela democratização da educação se constituiu em um "compromisso sócio-político, com o enfrentamento concreto e objetivo das questões de exclusão, tão comuns na educação brasileira, da reprovação e do não-acesso que reforçam pela escola, a marginalização das classes populares" (MARTINS, 1998, p. 58, grifo nosso). De organização racional, excludente e extremamente planificada, a escola passou a ser compreendida como uma instituição em que os aspectos sociais, culturais, políticos e econômicos permeiam o seu desenvolvimento, não devendo as decisões educativas ficar restritas a um pequeno grupo. Com isso, a construção do projeto de escola democrática, incorporou novos atores sociais: professores, alunos, pais e a comunidade, além dos que estavam em sua gestão, possibilitando uma nova forma de compartilhamento das decisões.

A incorporação desses atores sociais está respaldada pela compreensão de que a participação política é imprescindível para o êxito da democracia, correspondendo a um conjunto variado de atividades que implicam em: o ato de votar, na militância partidária, nas reivindicações sociais, no envolvimento nos debates políticos, na participação em espaços de decisão, na pressão exercida sobre os que exercem o poder decisório ou outros aspectos que se manifestam para assegurar os direitos da sociedade (BOBBIO; MATTEUCCI; PASQUINO, 1998), entre eles, o da educação.

Mesmo se intensificando nos anos de 1980, como dito anteriormente, é no contexto dos anos de 1990 que os debates sobre gestão educacional democrática se colocaram em evidência, defendendo a ideia de que a participação da sociedade contribuiria para a melhoria da qualidade da educação. Portanto,

\begin{abstract}
Gestão educacional corresponde ao processo de gerir a dinâmica do sistema de ensino como um todo e de coordenação das escolas em específico, afinado com as diretrizes e políticas educacionais públicas, para a implementação das políticas educacionais e projetos pedagógicos das escolas, compromissados com os princípios da democracia e com métodos que organizem e criem condições para um ambiente educacional autônomo (soluções próprias, no âmbito de suas competências) de participação e compartilhamento (tomada conjunta de decisões e efetivação de resultados), autocontrole (acompanhamento e avaliação com retorno de informações) e transparência (demonstração pública de seus processos e resultados). (LÜCK, 2010, p. 35-36).
\end{abstract}

Ao se pensar na concretização da gestão democrática na escola, consideramos que ela se constitui em um processo de formação de sujeitos capazes de atuar politicamente em seu cotidiano, problematizando sobre as condições de funcionamento da escola, refletindo sobre as dificuldades existentes e propondo as soluções necessárias para a melhoria do que se apresenta. Dessa forma, a participação de todos os segmentos torna-se importante para mudar a correlação de forças que se faz presente nas instituições educacionais, tendo em vista a existência de atitudes centralizadoras por muitos dos que estão na gestão da educação. Nesse sentido,

[...] a gestão democrática é entendida como processo de aprendizado e de luta política que não se circunscreve aos limites da prática educativa mais vislumbra, nas especificidades dessa prática social e de sua relativa autonomia, a possibilidade de criação de canais de efetiva participação e de aprendizado do "jogo" democrático e consequentemente, do repensar das estruturas de poder autoritário que permeiam as relações sociais e, no seio dessas, as práticas educativas. (DOURADO, 2011, p. 95-96).

Portanto, a materialização da gestão democrática depende da adoção de mecanismos que possibilitem o envolvimento da comunidade, destacando-se: a eleição dos gestores, a elaboração do projeto político-pedagógico e a existência e funcionamento de órgãos colegiados, com destaque para o Conselho Escolar. A institucionalização dos referidos mecanismos é resultante das lutas pela democracia, pois à medida que se obtêm o maior número de conquistas democráticas, como acesso e permanência na escola pública com qualidade social, as práticas educacionais, entre elas, a de 
gestão da escola, podem pautar-se na afirmação da liberdade de opiniões, visando o engajamento no espaço público do coletivo de sujeitos para sua realização.

Os conselhos escolares foram oficializados pela LDB 9.394/98, ao determinar como um dos princípios da educação nacional "a gestão democrática do ensino público" (art. $3^{\circ}$, inciso VII), e, ainda, no art. 14, ao definir que as normas de gestão democrática ao serem estabelecidas pelos sistemas de ensino, deverão ser pautadas na: "I- participação dos profissionais da educação na elaboração do projeto político-pedagógico da escola; II- participação das comunidades escolar e local em conselhos escolares ou equivalentes"; os debates com esses temas permaneceram no foco dos trabalhos da área educacional e nos discursos dos dirigentes dos estabelecimentos públicos de ensino. Contudo, a forma de gestão que se apresenta nas escolas tem se orientado pela concentração das decisões nas mãos dos gestores, por projetos políticos-pedagógicos que não passam de documentos sem utilidade, e pela fragmentação das instâncias colegiadas, a exemplo dos Conselhos Escolares, espaços em que a participação política se torna necessária para as deliberações a favor da educação.

\section{O PAPEL DOS CONSELHOS ESCOLARES NA DEMOCRATIZAÇÃO DA GESTÃO: elementos} constituintes do processo representativo

A democratização da gestão escolar ocorre por intermédio da criação de espaços participativos, nos quais os segmentos da escola contribuem com as decisões tomadas para a melhoria da qualidade do ensino. Contudo, "[...] é preciso ressaltar que a presença dos pais, famílias e demais usuários no interior da escola não constitui novidade histórica. Ela tem sido estimulada há décadas no âmbito de várias concepções pedagógicas e lutas da sociedade [...]" (SPÓSITO, 2001, p. 46-47, grifo nosso), na tentativa de institucionalizar na escola órgãos colegiados dos processos decisórios.

De acordo com Mendonça (2000), as primeiras experiências de democratização da escola com a implementação de órgãos colegiados ocorrem no final da década de 1970, em especial nas cidades de São Paulo e Minas Gerais, como espaços de tomadas de decisões e de ação coletiva da comunidade, para contribuir com os avanços dos aspectos administrativos e pedagógicos, possibilitando, dessa forma, uma nova cultura na organização da escola, com foco na participação. Esses colegiados (Conselhos Escolares) possuíam caráter apenas consultivo, com a presença de professores e técnicos que tinham a responsabilidade de auxiliar os (as) diretores (as) de escolas (ANTUNES, 2002).

Com a redemocratização, os conselhos escolares passam a ser considerados espaços de discussão, debate e reflexão nos quais o poder decisório fica a cargo da comunidade, propiciando à escola o exercício de sua autonomia. Desse modo, por meio de representantes dos segmentos de professores, pais, alunos, funcionários e comunidade local, eles devem acompanhar o trabalho pedagógico, administrativo e financeiro das escolas, tornando-se um local de exercício da cidadania e de participação da sociedade.

Nesse sentido, constituem parâmetros para seu funcionamento o cumprimento das funções:

a) Deliberativa - refere-se às decisões que o Conselho Escolar toma acerca do Projeto Político-Pedagógico da escola e outros assuntos, aprovando encaminhamentos para os problemas e garantindo a elaboração das normas de funcionamento interno da instituição em cumprimento as normas dos sistemas de ensino, propondo à gestão as ações a serem desenvolvidas;

b) Consultiva - quando analisa as questões encaminhadas pelos diversos segmentos da escola e apresenta as sugestões ou soluções que podem ser acatadas pela gestão;

c) Normativa - elaboração de normas de funcionamento da escola nos aspectos pedagógico, administrativo e financeiro;

d) Fiscalizadora - quando acompanha a execução das ações pedagógicas, administrativas e financeiras, avaliando e assegurando o cumprimento das normas da escola e a qualidade social da educação (BRASIL, 2004).

Desse modo, cabe aos Conselhos organizar debates, estudos e assumir a função de indutor das discussões que podem contribuir com a mudança da realidade educacional, a partir da ação coletiva e permanente de seus representantes e dos segmentos presentes na escola. Contudo, em cada realidade a atuação de conselhos escolares depende dos direcionamentos que são dados para o seu funcionamento e das articulações existentes para que o processo de representação não 
se restrinja apenas aos que são eleitos, implicando na socialização do poder para a comunidade escolar. Mas, resta a pergunta: como ocorre a representação nas escolas da rede pública de ensino? $\mathrm{Na}$ tentativa de responder a esse questionamento situamo-nos em uma realidade específica: a rede pública municipal de ensino da cidade de São Luís/MA. Nesse contexto, realizamos a pesquisa em duas escolas de ensino fundamental (Escolas "A" e "B"), utilizando como instrumento de coleta de dados entrevista semiestruturada com os conselheiros escolares e gestoras.

\subsection{A eleição de conselheiros e os limites da representação: o que dizem os representantes}

Um dos elementos mais importantes para a consolidação da democracia tem sido a forma de participação da sociedade nos espaços que permitem a reunião de pessoas para definirem os caminhos a fim de alcançar os objetivos propostos pelas instituições políticas e sociais. Nesse sentido, para constituir a democracia representativa ${ }^{1}$ como modelo de representação política, há de ser adotado o procedimento eletivo, por meio do voto, para a escolha daqueles que teriam as melhores condições de participar dos momentos decisórios.

Ao ser escolhido para "estar no lugar de" (CHAUÍ, 1990, p. 286), o representante toma para si a responsabilidade de intermediar os interesses dos seus representados mesmo que para isso não exista a obrigatoriedade de consultá-los com antecedência para tomar o seu posicionamento a favor ou contra os atos administrativos do Estado.

No que concerne ao funcionamento de Conselhos, consideramos ser imprescindível a representação proporcional de todos os segmentos que compõem a escola a fim de assegurar a diversidade de opiniões e oportunizar a democratização das votações que acontecem no seu interior. Assim, torna-se fundamental compreender os elementos que constituem os processos representativos nos Conselhos Escolares. Embora sendo cientes de que muitos elementos estão presentes nessa compreensão, no presente texto centramos nosso olhar nos mecanismos adotados para a escolha de conselheiros (representantes dos segmentos da escola) e na percepção que estes possuem acerca dos limites de sua atuação.

Para retratar a realidade das escolas pesquisadas, no que se refere aos mecanismos adotados para a escolha de conselheiros, as primeiras falas que nos apropriamos foram das presidentes dos Conselhos". A partir dos seus relatos constatamos que na escola "A" houve um aligeiramento do processo ocasionado pelo término do mandato dos conselheiros, com isso foi necessário fazer uma divulgação muito rápida e substituir a eleição pela realização de uma assembleia na qual os presentes escolheram seus respectivos representantes. Mesmo existindo a inscrição de candidatos para a representação dos segmentos, a presidente do Conselho da escola " $A$ " fez referência à falta de interesse das pessoas em se tornarem membros do Conselho escolar, esse fato foi ocasionado pelo pouco tempo entre o período das "candidaturas" e a escolha de representantes e a ausência de publicidade sobre a constituição do Conselho.

No caso da escola "B", percebemos a existência de uma melhor organização na forma de escolha de representantes, a começar pela publicação do edital para que as candidaturas se efetivassem e de uma divulgação mais sistemática, uma vez que a equipe responsável pelo pleito se preocupou em deixar ciente todos os segmentos da escola sobre a realização da escolha de representantes. Embora com toda essa organização, durante o processo eleitoral houve ausência de professores e pais, o que resultou em um número de presente menor do que o esperado.

Essas situações apresentadas nas falas das presidentes de Conselhos Escolares, reafirmam a ideia de que existe um "[...] estado de indiferença pelo funcionamento do sistema político [...]. [...] correlacionado com vários elementos: com a ausência de reais alternativas políticas, com a função desestimulante dos sistemas eleitorais [...], com a desordem e a instabilidade dos governos [...]" (CERRONI, 1993, p. 95-96). Outro ponto a ser referenciado é que o procedimento adotado pela escola "A" fere o que está colocado no Estatuto dos Conselhos Escolares da rede municipal de ensino de São Luís/MA, ao determinar que a escolha de conselheiros realizar-se-á por meio "[...] de eleição direta com voto secreto" (art. $40^{\circ}$ ), mas na escola foi realizada uma assembleia em que os participantes levantaram as mãos para escolher os seus representantes.

\footnotetext{
1 É importante lembrar que a democracia representativa foi instituída no mundo moderno para fazer valer o que ficou conhecido como soberania do povo, ao escolher aqueles que o representariam no parlamento.

2 Obedecendo ao que é determinado pelo Art. 18, § 1º do Estatuto dos Conselhos Escolares (SÃO LUÍS, 2004), esta função é ocupada em todas as escolas da rede pública municipal de São Luís/MA por aqueles (as) que estão no cargo de gestor (a) escolar.
} 
Ao descreverem sobre os mecanismos adotados na escolha de conselheiros, as representantes das professoras e funcionárias nos informaram, no caso da escola "A", sobre a "realização de uma assembleia" (Representante dos professores no C.E da escola "A") e de "uma reunião" (Representante dos funcionários no C.E da escola "A"), entretanto enfatizaram que esse procedimento aconteceu apressadamente, ao ser marcada uma reunião houve uma breve informação do que se tratava e os representantes foram escolhidos quando esta foi realizada.

Na escola "B", apareceu a opção pela "realização de eleição" normatizada pela publicação de um edital que trazia os requisitos necessários àqueles que desejassem ser candidatos, possibilitando que eles apresentassem as suas propostas para a comunidade escolar e, consequentemente, pedissem votos para os segmentos que representam. Ressaltamos que na escola "A", antes da realização da assembleia, a gestora da escola conversou previamente com as pessoas que se colocaram como candidatos a representantes dos segmentos, existindo uma indução no processo de escolha, descontruindo-se, dessa forma, as condições para uma indicação baseada no desejo individual de participar do Conselho Escolar.

Ao realizar uma assembleia apressadamente, a presidente do C.E da escola " $A$ " minimizou a importância que o processo de escolha de representantes tem para o pleno funcionamento do Conselho Escolar, ao desprivilegiar uma melhor organização dos segmentos para consolidar as candidaturas, essa representação corre o risco de não funcionar adequadamente para atender às demandas dos representados. Por outro lado, ao adotar a eleição como fez a escola "B", percebemos uma preocupação com a utilização de mecanismos democráticos de representação e participação social, gerando uma expectativa de que os procedimentos adotados possibilitem o desenvolvimento dos espaços institucionais em que os segmentos da escola têm oportunidade de expressar as suas ideias e colaborar com os trabalhos desenvolvidos.

A formação para a cidadania é uma das funções precípuas da escola. Nesse espaço, a participação não deve ser restrita aos professores e funcionários, portanto, ao possibilitar a representação do segmento de alunos no Conselho Escolar essa se constitui "[...] na relação com o outro, no grupo social instituído [...]" (BORDIGNON; GRACINDO, 2000, p. 157), em uma ferramenta para democratização da participação nos espaços representativos socialmente construídos. Ao opinarem acerca dos mecanismos adotados para a escolha de representantes, os procedimentos descritos pelos representantes de alunos estão em consonância com o revelado pelos representantes de professores e funcionários.

Nas falas apresentadas, destacamos que na escola " $A$ " a escolha se realizou por meio de um convite direto a uma aluna no momento em que "[...] a diretora passou nas salas de aulas para falar sobre uma reunião [...] ela entrou na minha sala e ela me chamou e me pediu para eu ser líder de todos os alunos da escola [...]" (Representante de alunos no C.E da escola "A"). Essa liderança significa a participação da aluna como representante do seu segmento no Conselho Escolar, mas essa deve se consolidar a partir dos desejos dos demais alunos e não com a influência de quem está na gestão da escola. Assim, a escolha deve ser realizada sem indicação prévia, baseada nas avaliações dos representados acerca das condições que possuem os candidatos para cumprirem as funções inerentes ao ato da representação. Pelo que percebemos no depoimento, os demais alunos da escola conheceram a aluna que seria escolhida como representante apenas no dia da assembleia, quando foi apresentada pela gestora da escola como candidata. Ou seja, ela não apresentou a sua proposta de trabalho aos demais alunos, o que nos faz inferir que a representante desse segmento não possuía um parâmetro para suas ações no Conselho.

Seguindo uma orientação democrática, na escola "B", a escolha do representante de alunos deu-se por meio de eleição. Na fala do representante constatamos que o mesmo estuda no turno noturno, mas possui um filho matriculado na escola pela manhã, a sua candidatura ocorreu depois que "[...] A diretora passou nas salas e leu um documento que dizia o período para se candidatar e o dia da eleição" (Representante dos alunos no C.E. da escola "B"). Uma das principais condições para ser representante de alunos nos Conselhos Escolares das escolas municipais de São Luís é ter idade mínima de 14 anos $^{3}$, impossibilitando a candidatura dos alunos com idade inferior e que estejam matriculados até o oitavo ano do ensino fundamental. No caso de alunos eleitos com idade de 14 anos, o seu tempo de permanência é no máximo por 12 meses, sendo que a escolha dos representantes ocorre após o início do ano letivo, esse período se reduz, então, para dez meses.

$3 \mathrm{O}$ art. 33 do estatuto dos Conselhos escolares considera membros efetivos, entre outros, alunos maiores de 14 anos, não sendo permitida a participação daqueles que possuem idade inferior (SÃO LUÍS, 2004). 
Essa situação tem levado muitas escolas municipais a optarem pelos alunos da educação de jovens e adultos, estudantes do noturno, que podem permanecer mais tempo nos Conselhos.

Conhecer as diferentes perspectivas acerca das realidades existentes nas escolas nos faz atentar para os caminhos que são trilhados na construção de espaços democráticos. Nesse sentido, destacamos, ainda, o relato de representantes dos pais e da comunidade local sobre os mecanismos adotados para a escolha de representantes. Os relatos apresentados nos revelam que existem dificuldades para o envolvimento dos pais dos alunos e de pessoas da comunidade local nos Conselhos Escolares. Com isso, esses segmentos dificilmente estão representados, podendo até participar das eleições, mas sem muito comprometimento com os outros momentos que se realizam após a escolha dos conselheiros, no caso das escolas pesquisadas, encontramos a existência de representantes dos pais nas duas escolas, enquanto, a representação da comunidade local aparece apenas em uma.

Na escola "A" a representante dos pais afirmou que a escolha foi feita "[...] em um grande encontro organizado pela diretora da escola [...], nas outras falas esse é nomeado como assembleia ou reunião, constituindo-se em uma prática que se apresenta na fala de todos os segmentos, descumprindo, desse modo, a determinação de existência de eleição para composição dos Conselhos. Tornase importante destacar que a representante dos pais da escola "A" estava sendo reconduzida ao Conselho, pois, era integrante do Conselho no mandato anterior (2011-2013). Ao descreverem esse processo na escola "B", a representante dos pais e o representante da comunidade local afirmaram que o procedimento adotado para indicação dos membros do Conselho foi a eleição, e que mesmo existindo apenas um candidato, para a maioria dos segmentos esta constitui-se a melhor forma de consolidar o processo democrático de escolha de representantes para os Conselhos Escolares.

Como exercício de síntese, destacamos que a composição de Conselhos Escolares nas duas escolas pesquisadas possuem elementos que estão relacionados ao trabalho de mobilização realizado pelas gestoras das escolas. Nesse sentido, conseguiram que fossem escolhidos os representantes dos vários segmentos, nos quais:

[...]. Cada um tem a sua posição e está no Conselho a partir dela, ou seja, integra o Conselho por ser aluno ou aluna, aluno com uma determinada idade, num determinado turno da escola; por ser professor ou professora, que trabalha no diurno ou no noturno ou, ainda, num dos componentes curriculares, que está num certo nível de sua carreira e com maturidade profissional própria; por ser funcionário ou funcionária, desempenhando atividades diversas, como secretária, servente ou auxiliar administrativo desta escola. As posições diferenciadas trazem, como pressuposto, expectativas diferenciadas para a escola, seu funcionamento e propostas a ela relacionadas. O Conselho escolar é um grupo diferenciado em gênero, idade, saberes e possibilidades de contribuição. Cada representante da comunidade escolar e local, desde sua posição, pode contribuir de uma determinada maneira. (WERLE, 2003, p. 57 , grifo nosso).

$\mathrm{Na}$ escola "A" temos repetidamente os representantes dos segmentos afirmando que estão no Conselho para atender a um pedido da gestora, portanto, colaborando com a influência que ela possui nos momentos de deliberações. Relatos como esse são preocupantes, pois, para se constituir como órgão colegiado de democratização do poder, o Conselho deve ser formado por pessoas comprometidas com a melhoria da escola e que estabeleçam relação com a comunidade, ou seja, devem ser indicados pelos seus pares por meio da eleição. Estas práticas, em que as indicações de conselheiros ocorrem por quem está na gestão da escola, reforçam a existência de uma centralização das decisões, ou seja, o processo participativo não é dinâmico e nem existe uma articulação dos Conselhos com a comunidade escolar. Por outro lado, na escola "B", a publicação do edital, a divulgação na escola e a realização de eleição para que cada segmento pudesse escolher o seu representante esboça um processo de participação coletiva.

Portanto,

A escolha dos membros dos Conselhos Escolares deve-se pautar pela possibilidade de efetiva participação: o importante é a representatividade, a disponibilidade e o compromisso; é saber ouvir e dialogar, assumindo a responsabilidade de acatar e representar as decisões da maioria, sem nunca desistir de dar opiniões e apresentar as suas propostas, pois os 
Conselhos Escolares são, acima de tudo, um espaço de participação e, portanto, de exercício de liberdade. (BRASIL, 2004, p. 45).

O processo de representação dos segmentos não pode ficar restrito apenas aos momentos de escolhas de representantes, realizados a cada dois anos. Esse é o primeiro passo para que as escolas consigam construir uma cultura participativa, na qual todo e qualquer tipo de problematização colabore com a construção de um amplo debate que direcione a escola para o cumprimento da sua função de democratizar o saber e colaborar com a formação de cidadãos, tendo em vista que "[...] A prática democrática não se resume na indicação de seus representantes que imediatamente se desligam de seus representados [...]" (SPÓSITO, 2001, p. 51). A participação permanente de representantes só é possível com a garantia de que todos reconheçam a importância da representação para o funcionamento do Conselho Escolar e qual o seu papel na escola.

Constituídos por representantes da comunidade escolar e local, suas principais funções direcionam-se para os aspectos administrativos, pedagógicos e financeiros da escola, a partir das ações que são desenvolvidas pelos conselheiros. Estes devem representar a comunidade no que se refere às tomadas de decisões e encaminhamentos das demandas que se fazem necessárias ao desenvolvimento dos processos educacionais.

Contudo, as realidades das escolas nos revelam que existem limites para consolidação do processo representativo. Nas falas das presidentes de Conselhos Escolares tais limitações são confirmadas, destacando-se como principais "[...] não ter o conhecimento pra que serve o Conselho, [...] conhecer os problemas da escola e participar das discussões [...]" (Presidente do C.E da escola "A"); e, "[...] a falta de contato entre quem está no Conselho e os representados [...]" (Presidente do C.E da escola "B"). Os limites apresentados nesses argumentos reforçam a ideia de que para fazer parte do Conselho é necessário ter um envolvimento com a instituição escolar e comprometerse com o processo representativo, conhecendo os documentos que normatizam o funcionamento do Conselho, suas atribuições e, ainda, ouvir cada segmento para saber os encaminhamentos necessários à melhoria dos trabalhos desenvolvidos nas escolas.

A condição para se romper os limites que impedem a efetividade do processo representativo deve partir da ação coletiva de representantes e, também, dos representados. Na formalização da representação nos Conselhos escolares explicita-se que esse processo só é possível quando cada segmento possui o seu representante e este consegue expressar a vontade daqueles que representam, mesmo que em muitos momentos esta seja diferente do seu próprio olhar sobre a realidade.

Nesse sentido, muitas estratégias têm sido adotadas para ampliar o envolvimento dos segmentos nas tomadas de decisões e nas ações promovidas nas escolas, dentre elas, o projeto políticopedagógico e o Conselho Escolar. De acordo com as falas das representantes dos professores e funcionários, além da falta de articulação existem outros elementos que limitam a representação. $\mathrm{Na}$ exposição da representante dos professores da escola "A" foi destacado como limite da representação "[...] a falta de encontro entre os segmentos [...]"; aqui ela não está se referindo aos encontros informais que acontecem pelos corredores da escola, ou na sala dos professores, mas aos que podem ser organizados para se refletir sobre as condições de funcionamento da escola e a elaboração de proposições a serem levadas ao Conselho Escolar com o objetivo de melhorar a realidade da instituição e, consequentemente, assegurar a democratização da gestão.

Por outro lado, a representante de professores da escola "B" realçou a "[...] falta de tempo [...]", sem o qual os representantes não conseguem organizar os seus horários para participarem das reuniões do Conselho e, muito menos, com seus representados. Nas escolas a situação em que vivem os professores, trabalhando em instituições diferentes para aumentar a renda familiar serve de exemplo de um processo representativo, que para dar certo depende de um maior compromisso de todos que dele fazem parte, portanto, da sociedade. Embora os docentes exijam que nos momentos de decisões sejam consultados, consideram as gestoras como aquelas que possuem as melhores condições de decidir o que é melhor para a escola pública. Isso se justifica, na visão das professoras, pelo conhecimento que possuem acerca da realidade escolar, ou pela relação que mantêm com o poder público, o que pode facilitar no atendimento das demandas educacionais.

Nas falas das representantes dos funcionários das duas escolas, o destaque principal diz respeito à falta de conhecimento sobre o que é o Conselho Escolar. Isso ocorre pela inexistência de 
formações cujas temáticas sejam voltadas ao Conselho, assim sendo, a resolução dos problemas fica centrada nas mãos da presidente do Conselho, pois, na compreensão das funcionárias ela sabe o que é melhor para a escola; ou seja, os demais representantes se retiram das discussões ou ficam de "[...] braços cruzados [...]", sem utilizar adequadamente o direito de voz que lhes cabe. Pelo que foi dito pelas representantes entrevistadas, o quadro que se apresenta nas escolas compromete a representação, formalmente, todos os segmentos estão representados, porém quando se trata de uma atuação efetiva não há o envolvimento desses representantes e, consequentemente, dos segmentos que representam.

Ao buscarmos as opiniões de representantes dos alunos acerca dos limites do processo representativo, percebemos que as poucas experiências de participação que são vivenciadas por esse segmento influenciam as percepções que possuem. A representante de alunos da escola "A" destacou a falta de conhecimento sobre a forma que deve agir em relação ao Conselho e, nesse sentido, afirmou "não saber direito o que tenho que fazer é um limite". Essa fala também está presente entre os representantes dos profissionais, o que indica a urgência da escola ou secretaria municipal de educação promover processos formativos que contribuam para um melhor funcionamento da representação.

No entendimento do representante dos alunos da escola "B", o tempo disponível é percebido como obstáculo para participação no Conselho, para ele "[...] a pessoa precisa ter tempo para vim 'pro' Conselho [...]", ou seja, independente do turno em que estude, o aluno precisa compartilhar as experiências vivenciadas no Conselho e participar das reuniões realizadas, porém, além de ser aluno, ele exerce uma atividade profissional que quase sempre o impede de comparecer às reuniões do Conselho. As justificativas de ausências às reuniões dos Conselhos por questões relacionadas à atuação profissional dos conselheiros se apresentam entre os professores, pais e alunos trabalhadores, nesse sentido, "[...] É preciso ajustar agendas, promover reuniões em horários acessíveis a todos, rastrear os ausentes, envidar esforços para reintegrá-los ao processo, fazer circularem os encaminhamentos tomados, participativamente, junto aos demais membros da comunidade escolar" (WERLE, 2003, p. 40).

Contudo, o desenvolvimento de práticas democráticas nas escolas continua sendo um dos grandes desafios da sociedade. Mesmo com a existência de Conselhos Escolares, a participação por meio da representação encontra caminhos tortuosos criados muitas vezes por quem tem a obrigação de propiciar as condições para sua realização. Desse modo, encontramos gestores que entendem o envolvimento dos professores, alunos, pais e comunidade local como uma intromissão nos assuntos que são de sua responsabilidade (PARO, 2001), porém, esses Conselhos são órgãos cuja função é limitar o poder centrado apenas nas mãos dos gestores.

$\mathrm{Na}$ concepção de Werle (2003), o Conselho Escolar é um importante espaço de aprendizagem democrática, que depende das relações existentes entre seus conselheiros; é, ainda, um local de discussão e construção de um projeto educacional fundamentado a partir dos interesses da comunidade. Ao serem questionados sobre os limites existentes ao funcionamento do Conselho, por meio da representação, as respostas dadas pelos representantes dos pais e da comunidade local reforçam a urgente necessidade de se rever o modo como eles funcionam.

A resposta da representante de pais da escola " $A$ " aparece na forma de desabafo, sendo obrigação da escola e da secretaria municipal de educação programar formações para os conselheiros e comunidade escolar saberem quais as suas atribuições. Nesse sentido, foi revelado como limite da representação "[...] saber mais o que temos que fazer [...] se soubesse ia ser melhor [...]". Essa falta de conhecimento sobre o que deve ser feito no Conselho é notória entre os representantes, por esse motivo a maioria não consegue cumprir suas obrigações. Embora direcione a culpa para a equipe da escola e secretaria de educação, lembramos que o estudo do Estatuto do Conselho, o conhecimento das pautas de reuniões, o levantamento das opiniões dos representados e a participação nas reuniões são ações que podem ser realizadas pelos representantes para melhorar as suas atuações. Nessa direção Antunes (2002, p. 40, grifo nosso), recomenda que:

Os membros do C. E. não devem ir para uma reunião sem saber os itens que serão abordados, pois correm o risco de tomar decisões equivocadas por não terem tido tempo de amadurecer suas opiniões. Além disso, os membros eleitos não estarão garantindo a representatividade, ou seja, não terão condições de consultar os seus pares para saber o que eles pensam a 
respeito de cada assunto e acabarão votando a partir de suas próprias avaliações, ou o que é mais comum, influenciados por quem tem o poder de decisão.

Na visão de representantes de pais e da comunidade local da escola "B" foram destacados especificamente dois limites para efetivação da representação. Nas duas falas apareceu a "falta de tempo" como um desses limites, assim, esse se torna o mais representativo entre os que foram relacionados pelos representantes de ambas as escolas: professores, alunos, pais e funcionários compreendem que participar das reuniões é importante, mas, nos horários em que são marcadas, geralmente, estão trabalhando ou em atividades relacionadas à escola, os alunos assistindo às aulas das disciplinas, e os professores nas salas de aulas dessas escolas ou em um segundo turno de trabalho em local diferente. O segundo é expresso pelo representante dos pais como "[...] falta de vontade de atuar corretamente [...]"; e, da comunidade local como "[...] desânimo [...]", isso porque as condições históricas de participação apesar de incluírem formalmente a representação dos segmentos das escolas, ainda, continuam sendo envolvidas por práticas que afastam muitos representantes dos processos decisórios. Nesse sentido, a fala do representante da comunidade foi significativa: "[...] as pessoas dizem as coisas e como não se realizam quem estar na escola vai deixando de acreditar que pode mudar [...]", ou seja, são promessas não cumpridas que colocam em xeque a democratização da escola e a participação da comunidade.

As falas desenvolvidas acerca dos limites do processo de representação nos revelaram que as condições existentes não contribuem para sua efetivação. Embora, em seu sentido geral, a representação tenha, também, o significado de "atuar para outros" (PITKIN, 2006, p. 27), na realidade das escolas pesquisadas percebemos que os representantes não possuem uma participação na qual essa atuação retrate a vontade dos representados, em primeiro lugar, pelas ausências às reuniões realizadas pelos Conselhos Escolares e, em segundo, pela falta de articulação por meio de reuniões ou outros mecanismos que sirvam para ouvir os seus pares e construir propostas a partir das suas manifestações.

Esses aspectos nos levam a inferir que o processo de representação presente nos Conselhos Escolares, está aquém do que é esperado para o alcance de uma participação mais efetiva da comunidade escolar nas decisões da escola. Portanto, incluir professores, pais, alunos, funcionários e comunidade local no debate sobre a conjuntura educacional é uma estratégia para melhorar as condições de ensino na escola pública e democratizar a sua gestão. Pelos elementos levantados, o problema que se inicia com a democracia representativa referente à ausência de relação dos representantes com seus representados perdura nos dias atuais e se faz presente na atuação dos conselheiros escolares das escolas pesquisadas, sendo necessário seu enfretamento para a democratização da gestão escolar.

\section{CONSIDERAÇÕES FINAIS}

A gestão democrática, mesmo com os avanços existentes, ainda, constitui-se em um grande desafio. Por esse motivo torna-se importante refletir acerca da materialização dessa forma de organizar as escolas em seus diversos contextos sociais, históricos, políticos, e, consequentemente, na diversidade geográfica do Brasil. Nossa pretensão no desenvolvimento deste artigo foi, portanto, contribuir com a ampliação desse debate, que como dissemos permanece atual, tendo em vista a existência de práticas decisórias centralizadoras.

No nosso entendimento, a superação das formas centralizadoras existentes nas escolas depende dos movimentos instituintes que direcionam para a participação mais efetiva da comunidade escolar, representada pelos segmentos dos professores, pais, alunos, funcionários e gestores, bem como da comunidade em que a escola está inserida. Assim, ao se tratar na democratização da gestão está implícita a utilização de instrumentos nos quais os referidos segmentos possam partilhar as decisões e se envolver diretamente nas ações da escola.

No direcionamento dado para o desenvolvimento do texto nos centramos na análise da especificidade de Conselhos Escolares da rede pública municipal de ensino da cidade de São Luís/MA. Embora existam muitos elementos que se relacionem ao funcionamento dos Conselhos, pontuamos aspectos referentes aos procedimentos utilizados para a escolha de conselheiros e os limites existentes ao processo de representação, a partir das opiniões de representantes. 
Em relação à escolha de conselheiros, notamos que as duas escolas apresentaram procedimentos diferenciados. Assim, mesmo existindo um direcionamento no estatuto dos conselhos escolares para que a escolha de representantes ocorra por meio de eleições secretas por segmento, na escola que denominamos de "A" foi realizada uma assembleia na qual os candidatos, predefinidos pela gestão da escola, tiveram seus nomes referendados pela comunidade escolar. Na escola "B", os caminhos traçados estão de acordo com o que é exigido em uma disputa democrática pelo voto, a saber: publicação de edital, candidaturas dos representantes, realização de campanha e de eleição, sendo escolhidos os representantes a partir dos interesses da comunidade.

Em uma democracia, a eleição constitui-se em um dos principais pontos para consolidar as práticas participativas, nesse sentido, sua realização deve se fazer presente em todos os espaços em que a representação se faz necessária para garantir que as decisões sejam tomadas pelo coletivo, portanto, defendemos que a escolha de representantes nos conselhos escolares seja realizada exclusivamente por meio da eleição, cumprindo-se aquilo que está posto no estatuto.

No que se refere aos limites do processo representativo percebemos que esse se inicia a partir da forma como os representantes são escolhidos, pois na escolha de conselheiros a partir da articulação das gestoras das escolas, como ocorre na escola "A", as decisões tomadas pelos mesmos tendem a ficar condicionadas às orientações dadas por quem as indicou. Além disso, temos a falta de envolvimento de representantes com as ações realizadas pelas escolas; o fato de os representantes dos pais e dos alunos não comparecerem as reuniões realizadas, mas, concordarem com as decisões que são tomadas pelos que se fazem presentes; a falta de conhecimento sobre as atribuições do Conselho escolar, relato presente nas duas escolas; e, a inexistência de formação para os conselheiros.

Embora existam muitos limites para efetivação do processo representativo, não devemos desconsiderar que a institucionalização de espaços participativos depende do compromisso de cada membro da comunidade escolar com a democratização da gestão da escola, sendo o Conselho Escolar um dos mecanismos de representação que pode contribuir para o envolvimento da escola em sua totalidade, constituindo-se em um espaço de aprendizado da democracia e, consequentemente, de formação de cidadãos críticos, o seu pleno funcionamento se torna fundamental para a construção de uma sociedade mais justa e igualitária. 


\section{REFERÊNCIAS}

ANTUNES, Â. Aceita um conselho?: como organizar o colegiado escolar. São Paulo: Cortez: Instituto Paulo Freire, 2002. (Guia da escola cidadã, v. 8).

BOBBIO, N.; MATTEUCCI, N.; PASQUINO, G. Dicionário de política. 11. ed. Brasília, DF: Editora Universidade de Brasília, 1998. v. 1.

BOGDAN, R. C.; BIKLEN, S. S. Investigação qualitativa em educação: uma introdução a teoria e aos modelos. Porto, Portugal: [s.n.], 1994.

BORDIGNON; G.; GRACINDO, R. V. Gestão da educação: o município e a escola. In: FERREIRA, N. S. C.; AGUIAR, M. A. da S. (Org.). Gestão da educação: impasses, perspectivas e compromissos. São Paulo: Cortez, 2000. p. 129-176.

BRASIL. Ministério da Educação. Secretaria de Educação Básica. Conselhos escolares: uma estratégia de gestão democrática da educação pública. Brasília, DF: MEC: SEB, 2004. (Programa Nacional de Fortalecimento dos Conselhos Escolares).

CERRONI, U. Política: métodos, teorias, processos, sujeitos, instituições e categorias. São Paulo: Editora Brasiliense, 1993.

CHAUÍ, M. de S. Cultura e democracia: o discurso competente e outras falas. 5. ed. São Paulo: Cortez, 1990.

DOURADO, L. F. A escolha de dirigentes escolares: políticas e gestão da educação no Brasil. In: FERREIRA, N. S. C. (Org.). Gestão democrática da educação: atuais tendências, novos desafios. 7. ed. São Paulo: Cortez, 2011. p. 93-115.
LÜCK, H. A evolução da gestão educacional, a partir da mudança de paradigma. Gestão em Rede, n. 3, p. 13-18, nov. 1997.

Gestão educacional: uma questão paradigmática. 7. ed. Petrópolis, RJ: Vozes, 2010. (Série Cadernos de Gestão).

MARTINS, R. B. Educação para a cidadania: o projeto político-pedagógico como elemento articulador. In: VEIGA, I. P. A.; RESENDE, L. M. G. (Org.). Escola: espaço do projeto político-pedagógico. Campinas, SP: Papirus, 1998. p. 49-86.

MENDONÇA, E. F. A regra e o jogo: democracia e patrimonialismo na educação brasileira. 2000. 323 f. Tese (Doutorado em Educação)- Faculdade de Educação, Universidade Estadual de Campinas, Campinas/SP, 2000.

PARO, V. H. Eleição de diretores de escolas públicas: avanços e limites da prática. In: tos sobre educação. São Paulo: Xamã, 2001.

PITKIN, H. F. Representação: palavras, instituições e ideias. Lua Nova, v. 67, p, 15-47, 2006.

SÃO LUÍS. Secretaria Municipal de Educação. Estatuto dos Conselhos Escolares. São Luís, 2004. Mimeografado.

SPÓSITO, M. P. Educação, gestão democrática e participação popular. In: BASTOS, J. B. (Org.). Gestão democrática. 2. ed. Rio de Janeiro: DP\&A; SEPE, 2001.

WERLE, F. O. C. Conselhos escolares: implicações na gestão da escola básica. Rio de Janeiro: DP\&A, 2003. 